\title{
On the evolution of clonal plant life histories
}

\author{
MARKUS FISCHER* and MARK VAN KLEUNEN \\ Institut für Umweltwissenschaften, University of Zürich, Winterthurerstr. 190, CH 8057 Zürich, \\ Switzerland \\ ("author for correspondence, tel.: +411 6354805; fax: +4116355711; e mail: fischerm@) \\ uwinst.unizh.ch)
}

\begin{abstract}
Clonal plant life histories are special in at least four respects: (1) Clonal plants can also reproduce vegetatively, (2) vegetative reproduction can be realised with short or long spacers, (3) and it may allow to plastically place vegetative offspring in benign patches. (4) Moreover, ramets of clonal plants may remain physically and physiologically integrated. Because of the apparent utility of such traits and because ecological patterns of distribution of clonal and non clonal plants differ, adaptation is a tempting explanation of observed clonal life history variation. However, adaptive evolution requires (1) heritable genetic variation and (2) a trait effect on fitness, and (3) it may be constrained if other evolutionary forces are overriding selection or by constraints, costs and trade offs. (1) The few studies undertaken so far reported broad sense heritability for clonal traits. Variation in selectively neutral genetic markers appears as pronounced in popu lations of clonal as non clonal plants. However, neutral markers may not reflect heritable variation of life history traits. Moreover, clonal plants may have been sampled at larger spatial scales. Empirical information on the contribution of somatic mutations to heritable variation is lacking. (2) Clonal life history traits were found to affect fitness. However, much of this evidence stems from artificial rather than natural environments. (3) The relative importance of gene flow, inbreeding, and genetic drift, compared with selection, in the evolution of clonal life histories is hardly explored. Benefits of clonal life history traits were frequently studied and found. How ever, there is also evidence for constraints, trade offs, and costs. In conclusion, though it is very likely, that clonal life history traits are adaptive, it is neither clear to which degree this is the case, nor which clonal life history traits constitute adaptations to which environmental fac tors. Moreover, evolutionary interactions among clonal life history traits and between clonal and non clonal ones, such as the mating system, are not well explored. There remains much interesting work to be done in this field which will be particularly interesting if it is done in the field.
\end{abstract}

Key words: adaptive evolution, clonal integration, constraint, environmental heterogeneity, for aging, genetic variation, guerilla and phalanx strategy, natural selection, phenotypic plasticity, sexual and vegetative reproduction, trade off

'It is a pleasure to see that you are still interested in the same questions that we used to ask some 30 years ago'. John L. Harper on the 5th Clonal Plant Workshop in Bangor, 1997.

'You can get it if you really want, but you must try.' Jimmy Cliff, 1970. 


\section{Introduction}

Among the modular organisms, clonal plants with potentially independent vegetative offspring (ramets) have particular life histories. Basically, clonal plants can do everything what non-clonal plants can do - and more. Their unifying main life-history characteristic is that they can reproduce not only sexually but also vegetatively. Because vegetative reproduction can be realised in many different ways (and as a consequence may result in different growth forms) and because it allows for selective placement of ramets and for integration between ramets, there is a large variation in clonal life histories. Moreover, clonal plants may express different life histories in different environments.

How did clonal life-history traits come about and how are they maintained? Evolution is driven by selection, genetic drift, inbreeding, gene flow, and mutation. Among these evolutionary forces, only natural selection may lead to adaptation which further requires heritable genetic variation and sufficient time. However, these prerequisites for adaptive evolution need not to be met. Moreover, even if they are, adaptive evolution may be prevented by physiological or physical constraints, trade-offs, or costs, or overriding importance of evolutionary forces other than selection (Stearns, 1992). Therefore, adaptive evolution constitutes one, but not the only evolutionary pathway.

Here we shortly introduce clonal life-history traits, and summarize information on their evolution. We emphasize the question in how far this evolution was and is adaptive, and discuss the role of constraints, trade-offs, costs, and of evolutionary forces other than selection in this context. Our goal is to identify open research questions which we hope will stimulate future work.

\section{Clonal plant life histories}

Clonal plants can reproduce sexually and vegetatively. In vegetative reproduction by clonal growth clonal plants may grow short or long spacers or both. The growth form associated with short spacers, termed phalanx strategy, and the one with long spacers, termed guerilla (Lovett Doust, 1981), constitute the ends of a continuum. Clonal growth does not necessarily follow a fixed growth pattern, but may actively serve to place ramets in more benign habitat patches (Harper, 1981; Bell, 1984; Schmid, 1990; Hutchings and de Kroon, 1994). This phenotypic plasticity may be termed foraging behaviour (Bell, 1984). Finally, ramets may remain physically connected and physiologically integrated (Pitelka and Ashmun, 1985). Clonal integration potentially allows for division of labour between ramets, which may specialise for certain tasks, such as sexual reproduction, nutrient uptake, or storage (Alpert and Stuefer, 1997).

Based on these considerations, we can define clonal life histories in the space spanned by the four dimensions of (1) vegetative vs. sexual reproduction and 
recruitment, (2) growth form, (3) the tendency for plastic foraging by selective ramet placement, and (4) the degree of clonal integration between ramets. Of these clonal traits, foraging per definition constitutes phenotypic plasticity, and the other traits may also respond plastically to different environments. It is interesting to note that all four dimensions are genet characteristics, which are more than the sum of ramet characteristics. (Throughout this paper, we deal with plants that reproduce vegetatively by means of clonal growth. For plants that produce vegetative offspring lacking the potential to remain connected to the parent plant, such as bulbils or agamic seed, only our considerations regarding vegetative vs. sexual reproduction apply.)

Clonal life-history traits do not evolve independently from each other. For example, plants with short spacers generally also have a higher rate of vegetative reproduction and a higher degree of physical (and possibly) physiological integration among modules (Lovett Doust and Lovett Doust, 1982; Schmid and Bazzaz, 1991; Stöcklin, 1992). However, high degrees of physical disintegration were found in a study of 24 perennial tussock-forming, i.e. phalanxtype, grasses (Wilhalm, 1995). Moreover, larger distances between ramets of guerilla plants suggest, that they experience steeper environmental gradients, which may lead to higher degrees of integration because they promote the transport of water and resources between ramets, and that selection for integration may have been stronger.

Moreover, clonal life-history traits are also not independent of non-clonal ones. For example, high degrees of phalanxness may result in mono-clonal patches were the availability of outcrossing pollen may be low (Charpentier et al., 2000) and the selfing rate high as a consequence of geitonogamous pollination between flowers of the same clone (Eckert, 2000). This in turn, can affect inbreeding depression and the evolution of the mating system. A high selfing rate may select for self-incompatibility, whereas low availability of outcrossing pollen may select for self-compatibility. The latter seems to be more important for clonal grasses, where phalanx species tend to be selfcompatible and guerilla species to be self-incompatible (Silander, 1985).

Clonality may also interact with seed dispersal and seed provisioning. In clonal plant populations with only initial seedling recruitment, small and easily dispersed seeds may be of advantage, while larger seeds may offer an advantage in populations with repeated seedling recruitment (Eriksson, 1989, 1997; Stöcklin and Favre, 1999).

Macroevolution and comparative studies among species

Clonality existed before sexual reproduction evolved, e.g. in microorganisms (Andrews, 1998). Nevertheless, clonal angiosperms were (most likely) derived 
from a non-clonal form (Takhtajan, 1980). Within the angiosperms the evolution of clonal plants from non-clonal ancestors has taken place many times and in many different taxa (Klimes et al., 1997).

Clonal angiosperms are more common in wet, nutrient-poor, cold, shaded (Tiffney and Niklas, 1985; Callaghan, 1988), and undisturbed habitats (Klimes et al., 1997). However, in many cases they are able to successfully colonise extremely disturbed areas such as road sides, wastelands, river and sea shores, where non-clonal plants are relatively rare (Fahrig et al., 1994). An obvious explanation for such ecological patterns of distribution is that clonal life histories constitute adaptations.

However, this explanation constitutes a hypothesis which needs to be tested. A classification according to the four clonal dimensions described above could allow the test of more precise hypotheses than just comparing between non-clonal and clonal plants. E.g., instead of asking whether clonal plants rather occur in undisturbed habitats than non-clonal plants do, we could more precisely ask whether a higher degree of vegetative recruitment among species is associated with a higher degree of disturbance of their habitats. Moreover, it may be hypothesized that more plastically foraging plants favour spatially more heterogenous habitats. Stöcklin (1992) found that guerilla species were more successful in open alpine habitats and phalanx in closed grasslands. Jonsdottir and Watson (1997) found that nutrient-poor habitats favoured clonally integrated species. Clonal plants with pronounced vegetative reproduction had lower rates of local extinction from nutrient-poor calcareous grasslands than plants without pronounced vegetative reproduction (Fischer and Stöcklin, 1997). This could be extended to a multivariate approach to elucidate which characteristics of clonal life histories are associated with, and possibly responsible for, the occurrence of a clonal plant in a particular habitat. To this end, a morphological classification such as the one of clonal plants in the flora of central Europe (Klimes et al., 1997) could be complemented with a more functional classification according to the four clonal dimensions, and with information on sexual life-history traits such as mating system, and the number and size of seeds. Criteria for the classification of the degree of integration have been developed by Jonsdottir and Watson (1997).

Growth form (phalanx vs. guerilla), plastic foraging, and clonal integration all have to do with the spatial arrangement of ramets of clonal plants. An optimal scale of spatial heterogeneity has been predicted for foraging responses (Sutherland and Stillman, 1988), and the scale of spatial heterogeneity plays a role in determining fitness in experiments in greenhouse and garden (Hutchings and Wijesinghe, 1997). Moreover, natural habitats are spatially heterogeneous at small scales (Lechowicz and Bell, 1991; Skalova et al., 1999). Given the recent emphasis on clonal integration, and especially on its benefits in spatially 
heterogeneous habitats, it is striking, that it is not known whether the spatial scale of heterogeneity in habitat characteristics matches the one of clonal growth and clonal integration. To date it has not even been shown, that clonal plants rather occur in heterogeneous habitats in nature.

\section{Microevolution}

The process of adaptation of a trait requires that the trait affects fitness and heritable genetic variation for the trait. If this process is going on for sufficient time, a state of adaptation may be reached, where different trait values optimise fitness in different environments. Such a state can be recognized by transplanting experiments, where fitness benefits and genetic variation should meet 'home-away' expectations for local adaptation (Schmid, 1985). This may be indicated by genotype-environment interactions with correspondingly crossing reaction norms for fitness (van Tienderen, 1992).

If the genotypes in heterogeneous environments encounter both environments, adaptive plasticity may evolve (Bradshaw, 1965; Scheiner and Lyman, 1991). This may lead to genotype-environment interactions in adaptive traits, when plants from heterogeneous and homogeneous environments are compared. The inspection of genotype-environment interactions in fitness and in life-history traits, therefore, provides an important tool in the study of adaptation of both plant traits and their plasticity.

\section{Fitness benefits of clonal traits and of their plasticity}

In clonal plants, there are several levels of selection, including the cell, the module, the ramet, groups of ramets, and whole genets (Sackville Hamilton et al., 1987; Tuomi and Vuarisalo, 1989; Keller, 1999). This makes the measurement and prediction of clonal plant fitness notoriously difficult (Winkler and Fischer, 1999). For practical purposes, fitness is frequently measured as biomass in experiments and as abundance in mathematical models.

All four clonal life-history traits appear to affect fitness. Mathematical models showed fitness effects of sexual vs. vegetative recruitment, which depended on the scale of disturbances (Winkler and Fischer, 1999) and on growth form, where phalanx species had an advantage at small disturbances and guerilla at large ones (Winkler and Schmid, 1995; Winkler et al., 1999). In further models, fitness effects were found for foraging (Sutherland and Stillman, 1988; Cain, 1994; Oborny, 1994; Cain et al., 1996), and for integration (Oborny et al., 2000), which also depended on the scale of spatial heterogeneity. Experiments showed fitness effects of growth form which depended on ramet density (Schmid and Harper, 1985; Humphrey and Pyke, 1998), and fitness benefits of foraging 
in a spatially heterogeneous competitive environment (van Kleunen and Fischer, 2001). Clonal integration was beneficial in spatially heterogeneous environments (Hutchings and Wijesinghe, 1997, and references therein), especially for steep environmental gradients (e.g. in nutrient availability for the stoloniferous Fragaria chiloensis; Friedman and Alpert, 1991).

Fitness as a phenotypic trait depends on both the genetic composition of an individual and on its natural environment. However, most life-history work has been done in artificial environments. While benefits of integration have been demonstrated in artificial heterogeneous environments (and integration even allowed for beneficial division of labour in reciprocally complementary environments; Stuefer et al., 1994), in the field integration mainly seems to serve for parental care (Alpert, 1995), and to enable invasion into unfavourable patches, such as salt pans (Pennings and Callaway, 2000). Among the artificial environments used to study clonal life-history traits, abiotic stress and competition have been emphasized, whereas other biotic interactions such as intraspecific density (Holler and Abrahamson, 1977; Schmid and Harper, 1985; Humphrey and Pyke, 1998), disease, herbivory (Schmid et al., 1988; Bach, 2000), and pollination (Saikkonen et al., 1998) received less attention. In the presence of disease clonal growth may be favourable because it may allow plants to escape (D'Hertefeldt and van der Putten, 1998). On the other hand, clonal integration may allow disease transmission between connected ramets. However, the likelihood of disease transmission decreases with internode length (Wenström and Ericson, 1992; Piqueras, 1999), which may result in a selection pressure for guerillaness in the presence of disease. Plants affected by disease and herbivory have been found to exchange signals via volatiles (Seskar et al., 1998; Dolch and Tscharntke, 2000). In clonal plants, internal signalling between ramets may facilitate induced plant defence and thus be important for the response to disease and herbivory. An alternative strategy for a clonal plant in the presence of parasites is to split into independent ramets, or at least to detach affected ramets (McCrea and Abrahamson, 1985).

A plastically reduced ratio of sexual relative to vegetative reproduction was found at higher intraspecific density (in Schmid and Harper, 1985 (Bellis perennis); Humphrey and Pyke, 1998), and an increased ratio also at higher density (Holler and Abrahamson, 1977; Schmid and Harper, 1985 (Prunella vulgaris) and in response to nutrient and light availability (van Baalen et al., 1990). Higher soil compactness caused a more compact growth form (Schmid and Bazzaz, 1990). While there is evidence that plasticity serves to actively place ramets in more benign habitat patches, this has not emerged as a general phenomenon (de Kroon and Hutchings, 1995). Plasticity in clonal integration has not been studied so far. However, e.g. resource sharing between ramets could be affected by the presence of herbivores, or be different in environments with different heterogeneous distributions of nutrients.

[348] 
Plastic responses may be passive and non-adaptive, or they may constitute adaptive plasticity with associated fitness benefits of the response. Passive plasticity may mask active plasticity if both are directed in different directions. E.g., under shading by competing plants the adaptive response would be internode elongation, but internodes may still grow shorter because of the competitive effect on nutrients. Therefore, the appropriate null model for active plasticity in internode length would be shorter internodes under unfavourable than under benign conditions (van Kleunen and Fischer, 2001). Benefits of plasticity in clonal traits have been shown in mathematical models, where plastically increased sexual reproduction was of advantage under poor conditions, because seed dispersal can act as an escape mechanism (Williams, 1975; Gardner and Mangel, 1999), and where growth form plasticity was of advantage, which enabled vegetative offspring to avoid occupied recruitment sites (Winkler and Schmid, 1995; see above for benefits of plastic foraging). Fitness benefits of plastic foraging have been experimentally confirmed in a heterogeneous competitive environment for a stoloniferous herb (van Kleunen and Fischer, 2001) but not for a grass with heterogeneously distributed soil nutrients (Humphrey and Pyke, 1997). However, field evidence for benefits of plasticity in clonal life-history traits is lacking.

\section{Genetic variation}

Although populations of clonal plants may consist of only a few large genets (Mitton and Grant, 1996), neutral genetic variation generally appears to be similar in populations of clonal and non-clonal plants (Widén et al., 1994; Ellstrand and Roose, 1987; McLellan et al., 1997). However, in comparative analyses of genetic variation between clonal and non-clonal plants potentially confounded phylogenetic effects were not taken into account (see Mazer, 1998 for a discussion of phylogenetic corrections in comparative analyses). Moreover, the reviews cited above compared studies without consideration of the spatial scale of sampling. Therefore, it can not be excluded that per-area measures of genetic variability are lower in clonal plants than in non-clonal plants, while they may not be on a per-population scale.

Genetic variation in plant populations is not only affected by the degree of clonality, but may also differ between clonal plants with different growth forms. Therefore, a classification of plant species only not just coarsely into clonal and non-clonal but plants into the classes of the four dimensions mentioned above could help to clarify the role of clonality for genetic variation in a population. Moreover, genetic variation may also be determined by the mating system, gene flow, population size, and environmental heterogeneity (Hartl and Clark, 1994). Moreover, clonal life-history traits may covary with environmental characteristics. For example, the effect of environmental het- 
erogeneity on genetic variation might be reduced in plants with high degrees of clonal integration. A classification of species according both to the clonal dimensions and to other factors affecting genetic variation could reveal the relative importance of clonal life histories for genetic variation.

With the increased availability of genetic markers the number of studies on neutral genetic variation in clonal plants has increased in recent years. However, what finally counts for the evolution of life-history traits is additive genetic (i.e. heritable) variation, which may not be revealed by neutral markers (Butlin and Tregenza, 1998; Prati, 1998). Past selection may have depleted additive genetic variation in life-history traits, and especially so because they are under stronger selection than other traits (Mousseau and Roff, 1987). However, this need not be the case because additive genetic variation in lifehistory traits may be maintained by several mechanisms, namely spatial or temporal variation in selection pressures (environmental heterogeneity), mutation-selection balance, genotype-by-environment interactions, flat fitness profiles, and negative genetic correlations due to antagonistic pleiotropy or linkage (Stearns, 1992; Falconer and Mackay, 1996; McLellan et al., 1997).

Unfortunately, studies on quantitative genetic variation in clonal life-history traits are scarce. Significant variation among genotypes of clonal plants has been reported for the allocation to sexual and vegetative reproduction (Schmid and Weiner, 1993; Prati and Schmid, 2000), for growth form and foraging, respectively (Cheplick, 1995, 1997; Humphrey and Pyke, 1997; Skalova et al., 1997; Cheplick and Gutierrez, 2000; van Kleunen et al., 2000a; van Kleunen and Fischer, 2001), and for clonal integration (Alpert, 1999; van Kleunen et al., $2000 \mathrm{~b}$ ). These studies underline the importance of using several genotypes in studies on clonal life histories (de Kroon et al., 1994). Moreover, the broadsense heritability demonstrated by variation among genotypes suggests that there is heritable variation in clonal life-history traits. However, in order to estimate narrow-sense heritabilities, which would demonstrate additive genetic variation, more sophisticated quantitative genetic studies are required, which use half-sib designs, parent-offspring regressions, or crossing designs (Falconer and Mackay, 1996).

There is quite some theoretical, but no empirical, information on the fate of mutations in clonal plants and on their importance for quantitative genetic variation. If there is no selection against mutations, somatic mutations were predicted to contribute as much or even more to genetic change than meiotic mutations (Orive, 2001). However, selection among cells will decrease the likelihood of fixation of deleterious mutations, and, compared with sexual offspring, especially so in multicellular vegetative offspring (Otto and Orive, 1995). The likelihood of fixation of mutations in apical meristems is larger in plants with unstratified meristems than in plants with stratified mersistems, which are found in most higher plants (Pineda-Krch, 2001). According to the 
somatic mutation theory of clonality (Klekowski, 1997), with increasing plant age meristems accumulate mutations, which reduce the likelihood of sexual reproduction. Therefore, evolutionary change becomes entirely dependent on very rare somatic mutations with advantageous phenotypic effects (Klekowski, 1997).

\section{Genotype-environment interactions}

In addition to the studies on genetic variation in plastic foraging mentioned in the previous section, there are only few other studies on genotype-environment interaction in clonal life-history traits. As a consequence of local adaptation reaction norms of genotypes originating from different habitat types may cross when they are reciprocally transplanted between home and away environments. Genotype-by-environment interactions which were in line with the local adaptation hypothesis have been found in Ranunculus reptans for the allocation to sexual and vegetative reproduction in response to interspecific competition (Prati and Schmid, 2000), and for foraging characteristics (van Kleunen et al., 2000b; van Kleunen and Fischer, 2001). These studies can be interpreted as evidence for broad-sense heritability of observed plasticity, and therefore suggest that plasticity in clonal life-history traits may evolve as an adaptation. However, it is not clear whether selection acts directly on plasticity itself or only indirectly, as a correlated response due to selection on mean values in single environments (Via, 1993; Scheiner, 1993; Schlichting and Pigliucci, 1998). Moreover, until now there is no information on narrow-sense heritability in plasticity of clonal life-history traits.

\section{Constraints on adaptive evolution}

Phylogenetic constraints may have prevented the adaptive evolution of clonal life-history traits in some taxa (van Groenendael et al., 1996). Moreover, even if there are fitness effects of and additive genetic variation in clonal life-history traits, their adaptive evolution may still be constrained for other reasons. Physical constraints could limit the evolution of clonal life-history traits, in a similar way as the length of internodes of non-clonal plants is limited by a critical buckling height (Niklas, 1988). Moreover, physiological or genetic trade-offs, i.e. negative genetic correlations, between life-history traits can constrain their evolution. For sexual vs. vegetative reproduction both kinds of trade-off have been reported (physiological: Watson and Caspar, 1984; Piquot et al., 1998; Prati, 1998; genetic: Geber et al., 1992; Prati and Schmid, 2000). The hierarchical organisation of clonal plants into ramets and genets may also lead to trade-offs between these levels, which, however, are hardly explored. A trade-off between ramet and genet size was reported in Trifolium fragiferum, 
where clones produced fewer but larger ramets if they were grown in higher vegetation (Huber and Wiggerman, 1997). Severing clones, i.e. disrupting clonal integration, led to the formation of more but smaller ramets in Scirpus maritimus (Charpentier et al., 1998). Another potential trade-off could be the one between foraging at the genet level (via plasticity in internode length to position ramets) and foraging at the ramet level (via plasticity in leaf length).

The evolution of clonal life-history traits may also be constrained by costs. Plants of Potentilla anserina with a high allocation to sexual reproduction in one season had to compensate this by a reduction in sexual reproduction in the following season (Saikkonen et al., 1998). Vegetative reproduction, on the other hand, may result in less developmentally stable offspring than sexual reproduction (Schmid and Bazzaz, 1990). There are several potential costs of clonal integration, such as costs of maintenance of the connecting tissues between ramets (Pitelka and Ashmun, 1985), the energy required for translocation between ramets (Epstein, 1972), the spread of pathogens through the connecting tissues (Cook, 1985; Wennström and Ericson, 1992, Piqueras, 1999), and the costs of translocation incurred by the source ramets (Caraco and Kelly, 1991). However, with the exception of the last one (Salzman and Parker, 1985; Stuefer et al., 1994; van Kleunen and Stuefer, 1999; van Kleunen et al., 2000b), these potential costs of integration have hardly been studied empirically.

Furthermore, phenotypic plasticity in clonal life-history traits may not only be beneficial, but may also incur costs. Several potential costs of plasticity have been identified, including costs for the maintenance of the physiological and genetic machinery for a plastic response (DeWitt et al., 1998). The only study on costs of plasticity in a clonal trait detected costs of horizontal foraging in R. reptans (van Kleunen et al., 2000a).

\section{Evolutionary forces other than selection}

In addition to the constraints on adaptive evolution mentioned in the previous section, adaptive evolution may be prevented if selection is overruled by other evolutionary forces such as inbreeding, genetic drift and gene flow (Hartl and Clark, 1994; Falconer and Mackay, 1996). However, studies on these other forces, which explicitly address the clonality of plants, are scarce.

Effective population size has been theoretically predicted to be smaller in clonal than in non-clonal plants which suggests a higher importance of genetic drift in clonal plants (Orive, 1993). However, empirical evidence of differentiation in neutral genetic variation among populations appears as large for clonal as for non-clonal plants, which suggests that genetic drift is as pronounced in clonal as in non-clonal plants (Fischer et al., 2000; Stehlik and Holderegger, 2000; Wolf et al., 2000). 
In clonal plants, geitonogamy may largely contribute to selfing (Eckert, 2000), and as a clone grows and produces more flowers, selfing is likely to increase (Handel, 1985). This might imply that selfing is stronger in clonal plants than in non-clonal plants. However, while this pattern was confirmed in a comparative study among species, it disappeared when a phylogenetic correction was applied (Klimes et al., 1997).

The degree of selfing and the relative importance of vegetative reproduction may affect the evolution of inbreeding depression. High levels of inbreeding may result in purging of genetic load, and if rates of selfing are higher in clonal than in non-clonal plants, this may result in lower inbreeding depression in clonal plants than in non-clonal plants. Moreover, increased selfing was predicted to increase the rate of fixation of favorable recessive mutations (Charlesworth, 1992). However, in a modeling study, the degree of asexual reproduction increased generation time and therefore generally increased inbreeding depression because it decreased the relative number of opportunities to purge genetic load (Muirhead and Lande, 1997). Moreover, purging of genetic load appears not to be a consistent force in evolution (Byers and Waller, 1999). Despite these theoretical considerations it is not known whether inbreeding depression is more or less severe in clonal than in non-clonal plants.

Little is known about differences in gene flow between clonal and non-clonal plants. Generally, clonal propagules are larger, more vulnerable to desiccation than seeds, and lack dormancy and any mechanisms to promote dispersal (Silander, 1985). Therefore, they may be expected to exhibit relatively limited dispersal compared to seed, and thus not to contribute much to gene flow. Nevertheless, even a small contribution of clonal growth will lead to overestimates of genetic neighborhood size if clonal growth is not considered (Gliddon et al., 1987). Clonal growth was even estimated to be the major source of gene flow for plants of $T$. repens older than 5 years (Gliddon and Saleem, 1985). There may be further examples for large contributions of clonality to gene flow, such as long-distance dispersal of floating clonal propagules of woody plants of lake or river shores.

\section{New methods for the study of microevolution of clonal plants}

There are several useful methods in microevolution which have hardly been applied to study clonal life histories. To see if trait variation affects fitness, phenotypic variation can be subjected to selection gradient analysis, where individual fitness measures are regressed on trait values (Lande and Arnold, 1983), or, to avoid biases due to environmental covariances between fitness and trait, genotypic fitness measures are regressed on genotype trait means (Rausher, 1992). Lacking phenotypic or genetic variation can be created by experimental manipulations. Phenotypic variation can be created using phy- 
tohormones, different light qualities for seedling growth (Schmitt et al., 1999), or by cutting plant parts, e.g. severing stolon internodes (Pitelka and Ashmun, 1985). Genetic variation can be created by crossing distinct ecotypes, which yields variable F2 progeny for further experimentation (Jordan, 1991). Enhanced genetic variation can also be studied in mutants and transgenic plants (Schmitt et al., 1999).

Heritability of and genetic correlations among traits may differ between environments (Falconer and Mackay, 1996), and therefore also between artificial and natural environments. Moreover, heritabilities may be overestimated in artificial environments of low variability (Roff and Simon, 1997). Heritable genetic variation in and genetic correlations between clonal life-history traits can be assessed in natural situations, when the relatedness among measured individuals is known from molecular markers (Lynch, 1999, Ritland, 2000). Moreover, Lynch (1999) recently developed a method to estimate genetic correlations in the field without knowledge of the relatedness among the measured individuals. The accuracy of this method increases with the number of and relatedness among individuals and higher heritability of the correlated traits.

Information from molecular genetic markers can be combined with quantitative genetic variation to identify so-called quantitative trait loci (QTL), i.e. loci that are responsible for quantitative genetic variation (Lynch and Walsh, 1998). This may allow to identify loci which affect clonal life-history traits. The relative effects of such loci on quantitative traits can be estimated with correlation analyses (Falconer and Mackay, 1996). To date, QTL analyses have not been applied to clonal life-history traits.

The recently developed cDNA microarray technology allows to directly study gene expression (Schaffer et al., 2000). It takes advantage of cDNA, i.e. DNA which is complementary to messenger RNA. cDNA from sampled plants can be hybridized with DNA sequences of known genes, which allows to detect gene expression. The use of chips with many genes and of robots allows to screen the expression of more than 1000 genes simultaneously (Schena et al., 1995). Among the current uses of the method is the study of induced plant defense (Schenk et al., 2000). Similarly, it could be applied to study the change in gene expression in plastic foraging responses to different environments. However, because this technique requires the knowledge of the function and sequence of genes, it is restricted to very few well-investigated model species, such as Arabidopsis thaliana and wheat. It will be interesting to see, in how far microarray chips designed for these species will also work in closely related clonal species.

Molecular genetic methods have already proven to be useful in distinguishing different genets of clonal plants. When molecular data are combined with spatial data on the location of ramets and on the distance between vegetative parent and offspring, they allow the estimation of the ratio of sexual vs. vegetative recruitment (Harada et al., 1997; Schläpfer and Fischer, 1998). Moreover, because 
molecular genetic markers are assumed to be selectively neutral, they provide useful tools in the study of non-adaptive evolutionary forces such as genetic drift, inbreeding and gene flow (Hartl and Clark, 1994; Ouborg et al., 1999).

\section{Conclusions}

It appears very likely that clonal life-history traits are adaptive. However, it is neither clear to which degree this is the case, nor which clonal life-history traits constitute adaptations to which environmental factors. Moreover, despite the considerable progress in the understanding of the ecology and evolution of clonal plants achieved in the last decades, our knowledge is still based on relatively few case studies, which almost exclusively deal with herbaceous, stoloniferous or rhizomatous, plants.

The most urgent open questions concern (1) fitness effects of clonal lifehistory variation in the field, (2) heritable variation in clonal life-history traits, (3) the contribution of somatic mutations to this variation, (4) the evolutionary interaction between different clonal traits and between clonal and non-clonal traits, (5) the evolutionary interaction of clonal traits with biotic interactions, (6) the role of phenotypic plasticity in clonal life histories, and (7) constraints, costs, and trade-offs. In addition to studies addressing single of these questions, comprehensive studies would be especially valuable.

There remains much interesting work to be done in this field - which will be particularly interesting if it is done in the field.

\section{Acknowledgements}

Our view of the evolution of clonal life histories has developed in stimulating discussions with Dani Prati, Bernhard Schmid, Jürg Stöcklin, and Eckart Winkler. The motivation to write this ms came from the 6th clonal plant workshop in Obergurgl, Austria. We thank Heidrun Huber, Christopher Eckert, Bernhard Schmid, Jürg Stöcklin, Josef Stuefer, and an anonymous referee for very constructive comments and helpful references. We acknowledge financial support by the Swiss National Science Foundation (Grant 31-49 728.96).

\section{References}

Alpert, P. (1995) Does clonal growth increase plant performance in natural communities? Abstr. Bot. 19, 1116

Alpert, P. (1999) Clonal integration in Fragaria chiloensis differs between populations: ramets from grassland are selfish. Oecologia 120, 6976 
Alpert, P. and Stuefer, J.F. (1997) Division of labour in clonal plants. In H. de Kroon and J. van Groenendael (eds) The Ecology and Evolution of Clonal Plants. Backhuys Publishers, Leiden, pp. 137154.

Andrews, J.H. (1998) Bacteria as modular organisms. Ann. Rev. Microbiol. 52, 105126.

Bach, C.E. (2000) Effects of clonal integration on response to sand burial and defoliation by the dune plant Ipomoea pescaprae (Convolvulaceae). Aust. J. Bot. 48,159 166

Bell, A.D. (1984) Dynamic morphology: a contribution to plant population ecology. In R. Dirzo and J. Sarukhan (eds) Perspectives on Plant Population Ecology. Sinauer, Sunderland, pp. 4865.

Bradshaw, A.D. (1965) Evolutionary significance of phenotypic plasticity in plants. Adv. Genet. 13, 115155.

Butlin, R.K. and Tregenza, T. (1998) Levels of genetic polymorphism: marker loci vs. quantitative traits. Phil. Trans. R. Soc. Lon. B 353, 187198.

Byers, D.L. and Waller, D.M. (1999) Do plant populations purge their genetic load? Effects of population size and mating history on inbreeding depression. Ann. Rev. Ecol. Syst. 30, 479513.

Cain, M.L. (1994) Consequences of foraging in clonal plant species. Ecology 75, 933944.

Cain, M.L., Dudle, D.A. and Evans, J.P. (1996) Spatial models of foraging in clonal plant species. Am. J. Bot. 83, 7685.

Callaghan, T.V. (1988) Physiological and demographic implications of modular construction in cold environments. In A.J. Davy, M.J. Hutchings and A.R. Watkinson (eds) Plant Population Ecology. Blackwell Scientific, Oxford, pp. 111135.

Caraco, T. and Kelly, C.K. (1991) On the adaptive value of physiological integration in clonal plants. Ecology 72, 8193.

Charlesworth, B. (1992) Evolutionary rates in partially self fertilizing species. Am. Nat. 140, 126 148.

Charpentier A., Grillas, P. and Thompson, J.D. (2000) The effects of population size limitation on fecundity in mosaic populations of the clonal macrophyte Scirpus maritimus (Cyperaceae). Am. J. Bot. 87, 502507.

Charpentier A., Mesleard, F. and Thompson, J.D. (1998) The effects of rhizome severing on the clonal growth and clonal architecture of Scirpus maritimus. Oikos 83, 107116.

Cheplick, G.P. (1995) Genotypic variation and plasticity of clonal growth in relation to nutrient availability in Amphibromus scabrivalvis. J. Ecol. 83, 459468.

Cheplick, G.P. (1997) Responses to severe competitive stress in a clonal plant: differences between genotypes. Oikos 79, 581591.

Cheplick, G.P. and Gutierrez, C.M. (2000) Clonal growth and storage in relation to competition in genets of the rhizomatous perennial Amphibromus scabrivalvis. Can. J. Bot. 78, 537546.

Cook, R.E. (1985) Growth and development in clonal plant populations. In J.B.C. Jackson, L.W. Buss and R.E. Cook (eds) Population Biology and Evolution of Clonal Organisms. Yale University Press, New Haven, pp. 259296.

de Kroon, H. and Hutchings, M.J. (1995) Morphological plasticity in clonal plants: the foraging concept reconsidered. J. Ecol. 83, 143152.

de Kroon, H., Stuefer, J.F., Dong, M. and During, H.J. (1994) On plastic and non plastic variation in clonal plant morphology and its ecological significance. Folia Geobot. and Phytotax. 29, 123138.

DeWitt, T.J., Sih, A. and Wilson, D.S. (1998) Costs and limits of phenotypic plasticity. Trends Ecol. Evol. 13, 7781.

D'Hertefeldt, T. and van der Putten, W.H. (1998) Physiological integration of the clonal plant Carex arenaria and its response to soil borne pathogens. Oikos 81, 229237.

Dolch, R. and Tscharntke, T. (2000) Defoliation of alders (Alnus glutinosa) affects herbivory by leaf beetles on undamaged neighbours. Oecologia 125, 504511.

Eckert, C.G. (2000) Contributions of autogamy and geitonogamy to self fertilization in a mass flowering, clonal plant. Ecology 81, 532542.

Ellstrand, N.C. and Roose, M.L. (1987) Patterns of genotypic diversity in clonal plant species. Am. J. Bot. 74, 123131.

Epstein, E. (1972) Mineral Nutrition of Plants: Principles and Perspectives. John Wiley and Sons, New York. 
Eriksson, O. (1989) Seedling dynamics and life histories in clonal plants. Oikos 55, 231238.

Eriksson, O. (1997) Clonal life histories and the evolution of seed recruitment. In H. de Kroon and J. van Groenendael (eds) The Ecology and Evolution of Clonal Plants. Backhuys Publishers, Leiden, pp. 211226.

Fahrig, L., Coffin, D.P., Lauenroth, W.K., and Shugart, H.H. (1994) The advantage of long distance clonal spreading in highly disturbed habitats. Evol. Ecol. 8, 172187.

Falconer, D.S. and Mackay, T.F.C. (1996) Introduction to Quantitative Genetics. Longman, Essex. Fischer, M. and Stocklin, J. (1997) Local extinctions of plants in remnants of extensively used calcareous grasslands 1950 1985. Cons. Biol. 11, 727737.

Fischer, M., Husi, R., Prati, D., Peintinger, M., van Kleunen, M. and Schmid, B. (2000) RAPD variation among and within small and large populations of the rare clonal plant Ranunculus reptans (Ranunculaceae). Am. J. Bot. 87, 11281137.

Friedman, D. and Alpert, P. (1991) Reciprocal transport between ramets increases growth of Fragaria chiloensis when light and nitrogen occur in separate patches but only if patches are rich. Oecologia 86, 7680 .

Gardner, S.N. and Mangel, M. (1999) Modeling investments in seeds, clonal offspring, and translocation in a clonal plant. Ecology 80, 12021220.

Geber, M.A., Watson, M.A. and Furnish, R. (1992) Genetic differences in clonal demography in Eichhornia crassipes. J. Ecol. 80, 329341.

Gliddon, C., Belhassen, E., and Gouyon, P.H. (1987) Genetic neighborhoods in plants with diverse systems of mating and different patterns of growth. Heredity 59, 2932.

Gliddon, C. and Saleem (1985) The adaptive significance of clonal reproduction in angiosperms an aquatic perspective. Aqua. Bot. 44, 159180.

Handel, S.N. (1985) The intrusion of clonal growth patterns on plant breeding systems. Am. Nat. $125,367384$.

Harada, Y., Kawano, S. and Iwasa, Y. (1997) Clonal identity probability: inferring the relative success of sexual vs. clonal reproduction from spatial genetic patterns. J. Ecol. 85, 591600.

Harper, J.L. (1981) The concept of populations in modular organisms. In R.M. May (ed.) Theo retical Ecology: Principles and Applications. Blackwell Scientific, Oxford, pp. 5377.

Hartl, D.L. and Clark, A.G. (1994) Principles of Population Genetics. Sinauer, Sunderland.

Holler, L.C. and Abrahamson, W.G. (1977) Seed and vegetative reproduction in relation to density in Fragaria virginiana (Rosaceae). Am. J. Bot. 64, 10031007.

Huber, H. and Wiggerman, L. (1997) Shade avoidance in the clonal herb Trifolium fragiferum: a field study with experimentally manipulated vegetation height. Plant Ecol. 130, 5362.

Humphrey, L.D. and Pyke, D.A. (1997) Clonal foraging in perennial wheatgrasses: a strategy for exploiting patchy soil nutrients. J. Ecol. 85, 601610.

Humphrey, L.D. and Pyke, D.A. (1998) Demographic and growth responses of a guerrilla and a phalanx perennial grass in competitive mixtures. J. Ecol. 86, 854865 .

Hutchings, M.J. and de Kroon, H. (1994) Foraging in plants: the role of morphological plasticity in resource acquisition. Adv. Ecol. Res. 25, 159238.

Hutchings, M.J. and Wijesinghe, D.K. (1997) Patchy habitats, division of labour and growth dividends in clonal plants. Trends Ecol. Evol. 12, 390394.

Jonsdottir, I.S. and Watson, M.A. (1997) Extensive physiological integration: an adaptive trait in resource poor environments? In H. de Kroon and J. van Groenendael (eds) The Ecology and Evolution of Clonal Plants. Backhuys Publishers, Leiden, pp. 109136.

Jordan, N. (1991) Multivariate analysis of selection in experimental populations of two ecotypes of the annual plant Diodia teres W. (Rubiaceae). Evolution 45: 17601772.

Keller, L. (1999) Levels of Selection in Evolution. Princeton University Press, Princeton.

Klekowski, E.J. (1997) Somatic mutation theory of clonality. In H. de Kroon and J. van Groen endael (eds) The Ecology and Evolution of Clonal Plants. Backhuys Publishers, Leiden, pp. 227 241.

Klimes, L., Klimesová, J., Hendriks, R. and van Groenendael, J. (1997) Clonal plant architecture: a comparative analysis of form and function. In H. de Kroon and J. van Groenendael (eds) The Ecology and Evolution of Clonal Plants. Backhuys Publishers, Leiden, pp. 130. 
Lande, R. and Arnold, S.J. (1983) The measurement of selection on correlated characters. Evolution $37,12101226$.

Lechowicz, M.J. and Bell, G. (1991) The ecology and genetics of fitness in forest plants. 2. Mi crospatial heterogeneity of the edaphic environment. J. Ecol. 79, 687696.

Lovett Doust, L. (1981) Population dynamics and local specialization in a clonal perennial $(R a$ nunculus repens). I. The dynamics of ramets in contrasting habitats. J. Ecol. 69, 743755.

Lovett Doust, L. and Lovett Doust, J. (1982) The battle strategies of plants. New Sci. 8, 8184. Lynch M. (1999) Estimating genetic correlations in natural populations. Gen. Res. 74, 255264.

Lynch, M. and Walsh, B. (1998) Genetics and Analysis of Quantitative Traits. Sinauer, Sunderland.

Mazer, S.J. (1998) Alternative approaches to the analysis of comparative data: compare and contrast. Am. J. Bot. 85, 11941199.

McCrea, K.D. and Abrahamson, W.G. 1985. Evolutionary impacts of the goldenrod ball gall maker on Solidago altissima clones. Oecologia 68, 2022.

McLellan, A.J., Prati, D., Kaltz, O. and Schmid, B. (1997) Structure and analysis of phenotypic and genetic variation in clonal plants. In H. de Kroon and J. van Groenendael (eds) The Ecology and Evolution of Clonal Plants. Backhuys Publishers, Leiden, pp. 185210.

Mitton, J.B. and Grant, M.C. (1996) Genetic variation and the natural history of quaking aspen. Bioscience 46, 2531.

Mousseau, T.A. and Roff, D.A. (1987) Natural selection and the heritability of fitness components. Heredity 59, 181197

Muirhead C.A. and Lande, R. (1997) Inbreeding depression under joint selfing, outcrossing, and asexuality. Evolution 51, 14091415

Niklas, K.J. (1988) Biophysical limitations on plant form and evolution. In L.D. Gottlieb and S.K. Jain (eds) Plant Evolutionary Ecology. Chapman and Hall, London, pp. 185220.

Oborny, B. (1994) Growth rules in clonal plants and environmental predictability a simulation study. J. Ecol. 82, 341351.

Oborny B., Kun, A., Czaran, T. and Bokros, S. (2000) The effect of clonal integration on plant competition for mosaic habitat space. Ecology 81, 32913304.

Orive, M.E. (1993) Effective population size in organisms with complex life histories. Theor. Popul. Biol. 44, 316340 .

Orive, M.E. (2001) Somatic mutations in organisms with complex life histories. Theor. Popul. Biol. $59,235249$.

Otto, S.P. and Orive, M.E. (1995) Evolutionary consequences of mutation and selection within an individual. Genetics 141, 11731187.

Ouborg, N.J., Piquot, Y. and van Groenendael, J.M. (1999) Population genetics, molecular markers and the study of dispersal in plants. J. Ecol. 87, 551568.

Pennings, S.C. and Callaway, R.M. (2000) The advantages of clonal integration under different ecological conditions: A community wide test. Ecology 81, 709716.

Pineda Krch, M. (2001) Evolution in multicellular mitotic lineages. PhD Thesis, University of Lund.

Piqueras, J. (1999) Infection of Trientalis europaea by the systemic smut fungus Urocystis trien talis: disease incidence, transmission and effects on performance of host ramets. J. Ecol. 87, 995 1004.

Piquot, Y., Petit, D., Valero, M., Cuguen, J., de Laguerie, P. and Vernet, P. (1998) Variation in sexual and asexual reproduction among young and old populations of the perennial macrophyte Sparganium erectum. Oikos 82, 139148.

Pitelka, L.F. and Ashmun, J.W. (1985) Physiology and integration of ramets in clonal plants. In J.B.C. Jackson, L.W. Buss and R.E. Cook (eds) Population Biology and Evolution of Clonal Organisms. Yale University Press, New Haven, pp. 399435

Prati, D. (1998) The genetics and life history evolution of the clonal plant Ranunculus reptans. PhD Thesis, University of Zurich.

Prati, D. and Schmid, B. (2000) Genetic differentiation of life history traits within populations of the clonal plant Ranunculus reptans. Oikos 90, 442456.

Rausher, M.D. (1992) The measurement of selection on quantitative traits: biases due to envi ronmental covariances between traits and fitness. Evolution 46, 616626. 
Ritland, K. (2000) Detecting inheritance with inferred relatedness in nature. In T.A. Mousseau, B. Sinervo and J. Endler (eds) Adaptive Genetic Variation in the Wild. Oxford University Press, New York, pp.187 199.

Roff, D.A. and Simon, A.M. (1997) The quantitative genetics of wing dimorphism under labora tory and 'field' conditions in the cricket Gryllus pennsylvanicus. Heredity 78, 235240.

Sackville Hamilton, N.R., Schmid, B. and Harper, J.L. (1987) Life history concepts and the population biology of clonal organisms. Proc. R. Soc. Lond. 232, 3557.

Saikkonen, K., Koivunen, S., Vuorisalo, T. and Mutikainen, P. (1998) Interactive effects of pol lination and heavy metals on resource allocation in Potentilla anserina L. Ecology 79, 16201629.

Salzman, A.G. and Parker, M.A. (1985) Neighbors ameliorate local salinity stress for a rhizoma tous plant in a heterogeneous environment. Oecologia 65, 273277.

Schaffer, R., Landgraf, J., Perez Amador, M. and Wisman, E. (2000) Monitoring genome wide expression in plants. Curr. Opin. Biotech. 11, 162167.

Scheiner, S.M. (1993) Genetics and evolution of phenotypic plasticity. Ann. Rev. Ecol. Syst. 24, 35 68.

Scheiner, S.M. and Lyman, R.F. (1991) The genetics of phenotypic plasticity. II. Response to selection. J. Evol. Biol. 4, 2350.

Schena, M., Shalon, D., Davis, R.W. and Brown, P.O. (1995) Quantitative monitoring of gene expression patterns with a complementary DNA microarray. Science 270, 467470.

Schenk, P.M., Kazan, K., Wilson, I., Anderson, J.P., Richmond, T., Somerville, S.C. and Manners, J.M. (2000) Coordinated plant defense responses in Arabidopsis revealed by microarray analysis. Proc. Nat. Acad. Sci. USA 97, 1165511660.

Schlapfer, F. and Fischer, M. (1998) An isozyme study of clone diversity and relative importance of sexual and vegetative reproduction in the grass Brachypodium pinnatum. Ecography 21, 351360.

Schlichting, C.D. and Pigliucci, M. (1998) Phenotypic Evolution: A Reaction Norm Perspective. Sinauer, Sunderland.

Schmid, B. (1985) Clonal growth in grassland perennials III. Genetic variation and plasticity between and within populations of Bellis perennis and Prunella vulgaris. J. Ecol. 73, 819830.

Schmid, B. (1990) Some ecological and evolutionary consequences of modular organization and clonal growth in plants. Evol. Trends Plants 4, 2534.

Schmid, B. and Bazzaz, F.A. (1990) Plasticity in plant size and architecture in rhizome derived vs. seed derived Solidago and Aster. Ecology 71, 523535.

Schmid, B. and Bazzaz, F.A. (1991) Growth of transplanted and native shoots in perennials with contrasting genet architecture. Flora 185, 335344.

Schmid, B. and Harper, J.L. (1985) Clonal growth in grassland perennials. II. Growth form and fine scale colonization ability. J. Ecol. 73, 809818.

Schmid, B. and Weiner, J. (1993) Plastic relationships between reproductive and vegetative mass in Solidago altissima. Evolution 47, 6174.

Schmid, B., Puttick, G.M., Burgess, K.H. and Bazzaz, F.A. (1988) Clonal integration and effects of simulated herbivory in old field perennials. Oecologia 75, 465471.

Schmitt, J., Dudley, S.A. and Pigliucci, M. (1999) Manipulative approaches to testing adap tive plasticity: phytochrome mediated shade avoidance responses in plants. Am. Nat. 154, S43 S54.

Seskar, M., Shulaev. V., and Raskin, I. (1998) Endogenous methyl salicylate in pathogen inocu lated tobacco plants. Plant Physiol. 116, 387392.

Silander, J.A. (1985) Microevolution in clonal plants. In J.B.C. Jackson, L.W. Buss and R.E. Cook (eds) Population Biology and Evolution of Clonal Organisms. Yale University Press, New Haven, pp. 107152 .

Skalova, H., Krahulec, F., During, H.J., Hadincova, V., Pechackova, S., and Herben, T. (1999) Grassland canopy composition and spatial heterogeneity in the light quality. Plant Ecol. 143, 129139.

Skálová, H., Pechácková, S., Suzuki, J., Herben, T., Hara, T., Hadincová, V. and Krahulec, F. (1997) Within population genetic differentiation in traits affecting clonal growth: Festuca rubra in a mountain grassland. J. Evol. Biol. 10, 383406. 
Stearns, S.C. (1992) The evolution of life histories. Oxford University Press, Oxford, UK.

Stehlik, I. and Holderegger, R. (2000) Spatial genetic structure and clonal diversity of Anemone nemorosa in late successional deciduous woodlands of Central Europe. J. Ecol. 88, 424435.

Stocklin, J. (1992) Environment, morphology and growth of clonal plants an overview. Bot. Helv. 102, 321 (in German).

Stocklin, J. and Favre, P. (1999) Differences in life history traits of related Epilobium species. Clonality, seed size and seed number. Folia Geobot. 34, 718.

Stuefer, J.F., During, H.J. and de Kroon, H. (1994) High benefits of clonal integration in two stoloniferous species, in response to heterogeneous light environment. J. Ecol. 82, 511518.

Sutherland, W.J. and Stillman, R.A. (1988) The foraging tactics of plants. Oikos 52, 239244.

Takhtajan, A.L. (1980) Outline of the classification of flowering plants (Magnoliophyta). Bot. Rev. 46, 225359.

Tiffney, B.H. and Niklas, K.J. (1985) Clonal growth in land plants, a paleobotanical perspective. In J.B.C. Jackson, L.W. Buss and R.E. Cook (eds) Population Biology and Evolution of Clonal Organisms. Yale University Press, New Haven, pp. 3566.

Tuomi, J. and Vuarisalo, T. (1989) What are the units of selection in modular organisms. Oikos 54, 227233.

van Baalen, J., Ernst, W.H.O., van Andel, J., Janssen, D.W. and Nelissen, H.J.M. (1990) Re productive allocation in plants of Scrophularia nodosa grown at various levels of irradiance and soil fertility. Acta Bot. Neerl. 39, 183196.

van Groenendael, J.M., Klimes, L., Klimesová, J. and Hendriks, F.J.J. (1996) Comparative ecology of clonal plants. Phil. Trans. R. Soc. Lond. B 351, 13311339.

van Kleunen, M. and Fischer, M. (2001) Adaptive evolution of plastic foraging responses in a clonal plant. Ecology 82, 33093319

van Kleunen, M. and Stuefer, J.F. (1999) Quantifying the effects of reciprocal assimilate and water translocation in a clonal plant by the use of steam girdling. Oikos 85, 135145 .

van Kleunen, M., Fischer, M. and Schmid, B. (2000a) Costs of plasticity in foraging characteristics of the clonal Ranunculus reptans. Evolution 54, 19471955.

van Kleunen, M., Fischer, M. and Schmid, B. (2000b). Clonal integration in Ranunculus reptans: by product or adaptation? J. Evol. Biol. 13, 237248.

van Tienderen, P.H. (1992) Variation in a population of Plantago lanceolata along a topographical gradient. Oikos 64, 560572.

Via, S. (1993) Adaptive phenotypic plasticity target or by product of selection in a variable environment. Am. Nat. 142, 352365.

Watson, M.A. and Casper, B.B. (1984) Morphogenetic constraints on patterns of carbon distri bution in plants. An. Rev. Ecol. Syst. 15, 233258.

Wenstrom, A. and Ericson, L. (1992) Environmental heterogeneity and disease transmission within clones of Lactuca sibirica. J. Ecol. 80, 7177.

Widén, B., Cronberg, N. and Widén, M. (1994) Genotypic diversity, molecular markers and spatial distribution of genets in clonal plants, a literature survey. Folia Geobot. Phytotax. 29, 245263.

Wilhalm, T. (1995) A comparative study of clonal fragmentation in tussock forming grasses. Abstr. Bot. 19, 5160 .

Williams, G.C. (1975) Sex and Evolution. Princeton University Press, New Jersey.

Winkler, E. and Fischer, M. (1999) Two fitness measures for clonal plants and the importance of spatial aspects. Plant Ecol. 141, 191199.

Winkler, E. and Schmid, B. (1995) Clonal strategies of herbaceous plant species: a simulation study on population growth and competition. Abstr. Bot. 19, 1728.

Winkler, E., Fischer, M. and Schmid, B. (1999) Modelling the competitiveness of clonal plants by complementary analytical and simulation approaches. Oikos 85, 217233.

Wolf, A.T., Howe, R.W. and Hamrick, J.L. (2000) Genetic diversity and population structure of the serpentine endemic Calystegia collina (Convolvulaceae) in northern California. Am. J. Bot. 87,11381146 